\title{
Metaphor and Simile as Expressions of Emotion Portrayed in the Novel The Devil Wears Prada
}

\author{
Kevin Jie \\ Balikpapan University \\ kevinjie4398@gmail.com
}

\begin{abstract}
:
The research aims to analyze metaphor and simile as the expression of emotion portrayed in the novel The Devil Wears Prada by Lauren Weisberger. There are two objectives of this research. The first one is to identify the tenor of metaphor and the simile within the novel. The second is how the metaphor and the simile express the expression of emotion within the novel. The theory used in this research are, the first is the semantic theory by Geoffrey Leech about the figurative language and the second theory is expression of emotion by Kovecses. The method used in this research is qualitative descriptive way. The data contained in this research is divided into primary and secondary data. Primary data is the novel The Devil Wears Prada, and the secondary data are sourced from the articles, journals, e-books, books and other references related to this research. The result of the research, the researcher found several types of figurative language such as metaphor and simile within the novel. Each of the figurative language expresses the expression of emotion such as happy emotion, angry emotion, fear emotion and love emotion. The research shows that metaphor is the most frequent types of figurative language found and the most frequent types of figurative language that express the emotion within the novel.
\end{abstract}

Keywords: metaphor, simile, emotion, The Devil Wears Prada 


\section{INTRODUCTION}

Figurative language is type of language which have various meaning in order to deliver the meaning from speakers to touch the emotion and persuade an action. Peter (2002) defines that "figurative language is a language which has figurative meaning and incorporates the speaker's desire to touch the emotions, to cause shock and to persuade into action (p.12). The figurative language does not have monotone meaning, the quotation explains in order to touch the emotions, to cause shock and persuade an of the readers, the meaning should be various. Miller (1981) states that "figurative language is an indirect statement that says one thing in terms or another" (p.66). Figurative language does not describe the meaning directly instead insists readers to apprehend the meaning indirectly.

The use of figurative language could imply various expression showed by people to be considered of other feelings instead of uttering it directly. Expression is used to express ideas and feelings by showing them through words, actions or artistic activities (Collins, 2020). The definition above defines that an expression is not limited by actions, face expression or gesture but expression could be considered by words. The researcher explains that the expression could be expressed by various forms consist of face expression, expression of vocal and body mimic. Each form has different example as shown above, all the various expressions depend on the individual's mood.

The emotion itself could be divided into six basics of emotions as Ekman (1992) states that "the six basic emotions are anger, disgust, fear, happiness, sadness, and surprise (p.169)". Those basic emotions have a specific characteristic attached to each emotion, anger associated with high tone voice, happiness associated with laugh and smile, sadness associated with tears. In the novel The Devil Wears Prada, the researcher found many uses of metaphor and simile as the expression of emotion, particularly when the main character struggles balancing her responsibility in work place environment, personal life with her boyfriend and family, and the complex relationship with her boss.

This research used figurative language approach to analyze this research. The researcher is interested in expanding the scientific research in the novel The Devil Wears Prada by using figurative language approach to analyze expression of emotion. Most of other figurative language research focuses on determining the type of figurative languages and the meaning of the figurative language also there is also another research on figurative language in a color and rarely figurative language research that focus on expression of emotion such as this research. By conducting this research, the researcher expects it could enrich reader's understanding, perception and knowledge of how to identify metaphor and simile as the expression of emotion. As the research topic is figurative language the approach of Geoffrey Leech is implemented for the analysis of this research.

\section{LITERATURE REVIEW}

In analyzing the novel The Devil Wears Prada, the researcher uses the theory of figurative language by Geoffrey Leech, and the researcher focuses on the expression of emotion through the use of figurative language. 


\section{Semantics}

Semantics is a study of meaning and study of communication. The study of semantics is important because communication is a crucial factor in social organization. Leech has defined the definition of semantic as below:

"Semantics (as the study of meaning) is central to the study of communication; and as communication becomes more and more a crucial factor in social organization, the need to understand it becomes more and more pressing. Semantics is also at the centre of the study of the human mind - thought processes, cognition, conceptualization - all these are intricately bound up with the way in which we classify and convey our experience of the world through language." (Leech, 1981, p. ix)

Semantics not only focuses on meaning and communication but also focuses on mental processes in order to express the story of the world through language and the meaning, communication and those mental process are bound to each other.

The meaning in semantic is divided into two important parts, literal meaning and non-literal meaning. Literal meaning deals with literal or dictionary meaning which same as denotation. Non-literal meaning is beyond the dictionary meaning which deals with connotation or figurative language. The expressing meaning through figurative language would be used in this research.

\section{Figurative Language}

Figurative language is a language aspect in which an expression is stated in the opposite way than its usual way. (Leech, 1969) highlights that it would be difficult to interpret without knowing the context being expressed in a text (p.147). Figurative language could be found in written or spoken expressions. Many of the expressions need special imagination and conceptualization to interpret their meanings. Figurative language is a nonliteral meaning to reflect the characteristic the novel itself and the researcher thoughts. The figurative language is used to enrich the knowledge and imagination.

\section{Metaphor}

Metaphor is one of figurative language branch, a figure of speech that describes an idea, object, action or make a comparison with a non-literal meaning unlike literal meaning. Leech has defined the metaphor as below:

"Metaphor ... making believe that tenor and vehicle are identical. But as many writers have observed, the pretence often seems more serious and more real than the 'real' world of literal understanding. Nevertheless, from a linguistic point of view, the literal meaning is always basic, and the figurative meaning derived" (Leech, 1969, p. 151)

From that statement, two different things could be compared by metaphor but unlike simile, metaphor does not use "like" and "as" to compare. Metaphor could not be properly understood unless seen against the background of the various other mechanisms of 
figurative expression. To elaborate the metaphoric rule, Leech provided an example as below:

"With the aid of the metaphoric rule, we actually understand 'Life is a walking shadow' as 'Life is like a walking shadow', or 'Life is, as it were, a walking shadow'. In notional terms, 'life' is the TENOR of the metaphor - that which is actually under discussion - and the purported definition 'a walking shadow' is its VEHICLE - that is, the image or analogue in terms of which the tenor is represented" (Leech, 1969, p. 151).

From the example above that given by Leech in his book, it could be understood that 'tenor' is something that being discussed or the major of the sentence that the meaning would be implied through the vehicle indirectly, 'vehicle' represents the tenor by the image or analogue which related to the transference meaning or in short, 'vehicle' is the figurative itself in metaphor.

\section{Personification}

As one of figurative language branch, personification is different from the other, personification has a unique characteristic which humanizing subjects or nonhuman organisms. According to Leech (1969), "The ... personification, whereby an abstraction is figuratively represented as human actually combines all three categories - concreteness, animistic and humanizing" (p.158). By combining all three categories, something nonhuman such as animals, objects, plants are given personality like human beings. Personification allows to create life and motion within inanimate objects, animals, and even abstract ideas by assigning them recognizable human behaviors and emotions.

\section{Simile}

Unlike metaphor, simile is way easier to compare two or more different things, events or actions. "A simile is a figure of speech in which two distinct things are compared by using the words like or as" (Leech, 1969, p. 156). In order to compare things which are fundamentally unlike, simile uses words such as "like" or "as" in short, simile is used to compare different things by using words such as like, as, similar, than, resemble or seems which the tenor and vehicle totally different.

\section{Synecdoche}

Synecdoche is a figure of speech in figurative language which represent part of the word from the whole. According to Leech (1969), "The traditional figure of synecdoche is identified with a rule which applies the term for the part to the whole" (p.150). The statement above means synecdoche is only the term for the part to the whole without mention all the words instead the representative of the word.

\section{Metonymy}

Metonymy is the use of an idea of something for another which it is an attribute or something that associated. Leech (1969) states that "Metonymy is a figure of speech that 
consists in using the name of one thing for that of something else with which it is associated" (p.152). Based on the definition above, the metonymy is a replacement an object or idea with something related to it, this figure of speech enables writers to express a thought by using a closely related word.

\section{Expression of Emotion}

Expression is a form of human feeling where mind and body are related each other, every individual has a different way to express them. A person uses the expression such as happy, angry, sad, hate and etc to deliver what they feel to other person. (Kovecses, 1990, p. 2) highlights that expression is used by people to put on feelings in order to convince others. In other word, expression is commonly a way for a person to show and express an emotion in life by using feelings to deliver a meaning or message.

\section{Forms of Emotion}

Expression itself has a various form in order to deliver the message to other. (Kovecses, 1990) argues that the expression consists of happy, love, anger, fear, lust, sad, pride, shame and guilt (p.3-43). In this research, the researcher focuses on limited forms of expression consists of happy, anger, love, fear and sad.

\section{Happy}

Happy is an expression to deliver feeling of pleased, joy and delighted. Happy could cause some gesture such as smile, laugh and cheer. The feeling of happy could be triggered by winning a lottery, doing something pleasure, making a dream comes true. Some expressions of happy such as 'I'm on top of the world'.

\section{Angry}

Angry is a strong feeling that involved uncomfortable and unpleasant response that caused by something unfair and unkind happened. Anger could cause a person to hurt, use a physical violence, insult and threat other person. A trigger of anger could be: lost someone, betrayed by someone, losing impatience, disrespect, abusive language, bullying, violation. An anger expression such as 'my face looks so red'.

\section{Love}

Love is a strong feeling of affection, fondness, warmth based on a person's experienced as for a parent, child, friend or partner. A trigger of love could be: an attraction to one another, sympathy, a family relation. A love expression such as: catch someone's eye, you are my vitamin of my day.

\section{Fear}

Fear is an unpleasant emotion, worried or awareness by something dangerous, painful or evil. Fear itself has some forms such as insecurity, anxious, shock or worry. When a person is in fear commonly that person keep a distance away from the source of the fear. A trigger of fear could be darkness, rejection, traumatic, death, heights. An expression of fear such as 'my blood run cold'. 


\section{5. $\mathrm{Sad}$}

Sad is used to express a disappointment, sorrow, grief, mournful, depression, misery because of something bad happened. Sad could be expressed by cry and frown, sometimes sad could also cause an anger. A trigger of sad could be: losing someone, death, depression, stress, bad memories. An expression of sad such as: feeling blue, cry one's eyes.

\section{RESEARCH METHODOLOGY}

In this research, the data collected by repeatedly reading the novel The Devil Wears Prada then classified the metaphor and simile in the novel. Next, the researcher lists the tenor of metaphor and simile and classify it into emotion. Furthermore, the researcher collects the secondary data regarding the topic of the research, which is the theory of Geoffrey Leech, specifically the metaphor and simile and the expression of emotion of Kovecses. The last step, the researcher identifies the tenor of metaphor and simile toward the emotion. The researcher uses descriptive qualitative research method to analyze the figurative language as the expression of emotion potrayed in the novel The Devil Wears Prada.

\section{FINDINGS AND DISCUSSION}

The findings and discussion section of this research is to explain the findings of this research. It contains the explanation about the tenor of metaphor and simile such as occupation, person, condition, personality, object, sign and emotion and how the metaphor and simile express the emotion in the novel The Devil Wears Prada. The researcher discusses the findings through analysis by Geoffrey Leech theory.

\section{Tenor of Metaphor and Simile}

The researcher found two types of figurative language in the novel, there are metaphor and simile. They are to be presented and explained as follows.

\section{Tenor of Occupation}

The researcher found there are some tenor metaphor of occupation within the novel. The tenor is used as the major of the sentence or something discussed that being interpreted by the vehicle in metaphor by Geoffrey Leech. In this section, occupations are represented by the vehicle that contains the metaphor in order to deliver the tenor.

"Ah, sure, Miranda, I thought to myself as I walked away, trying to figure out the first step in the assignment that was sure to have a million pitfalls along the way. First was definitely to find out at which 'place' the car was located. Most likely it was being repaired at the dealership, but it could obviously be at any one of a million auto shops in any one of the five boroughs". (Weisberger, p.4)

The researcher explains the excerpt as metaphor because it describes the assignment that Miranda gave with a million pitfalls. The researcher compares the assignment and million 
pitfalls of the excerpt. Denotatively, pitfalls are a trap holes made with the intention of trapping. Meanwhile, in connotative way, the assignment could not possibly shape like a trap hole but a obstacle that would be confronted by Andrea during the work. The tenor of this metaphor is assignment and the vehicle is million pitfalls. It could be concluded that the ground or the relation between the tenor and the vehicle is the assignment is a pitfall because Andrea was instructed to pick the card without any hint where the car is located.

"The chance to work for her, to watch her edit and meet with famous writer and models, to help her achieve all she does each and every day, well I shouldn't need to tell you that it's a job a million girls would die for". (Weisberger, p.17).

This excerpt is a metaphor because it describes the job that every girl craves for. The researcher compares the job with million girls would die for. Denotatively, would die for means every girl would give herself to die for that job, die which means not breathing and end their life in the world. However, in connotative way, would die for means it is a job that every girl want because the benefits of the job is precious. The tenor of this metaphor is job and the vehicle is million girls would die for. The ground between the tenor and the vehicle is the precious opportunity for every woman.

\section{Tenor of Person}

The researcher found there are some tenor metaphor of a person within the novel that being interpreted by the vehicle in metaphor by Geoffrey Leech. The tenor metaphor of person means that the person is the major of the sentence and the vehicle is used to interpret it through the metaphor of Geoffrey Leech approach.

"Just when something negative about Miranda slips out from a Clacker's lips - however justified - paranoia that Miranda will find out overwhelms the speaker and inspires an about-face. One of my favorite workday pastimes became watching my colleagues scramble to negate whatever blasphemy they'd uttered". (Weisberger, p.41)

The excerpt is a metaphor because it describes the staff with a clacker. The researcher compares the difference between the girls and a clacker. The Clacker in denotative way means a toy that popular in the late 1960s and early 1970s, they are formed out with two solid balls and attached to a finger tab using a sturdy string meanwhile in connotative way, clacker in this context means the similarity of the clacker's sound with the sound of the staff's shoes. The tenor of this metaphor is the girls who work at Runaway and the vehicle is clacker's lips. The ground or the similarity of this metaphor is the sound of the staff's shoes sounds like a clacker.

“Touché, Miranda's new assistant, touché. You and I m-m-may be friends after all. I d-d-d-don't much like the usual robots she hires, but it's fitting because I don't much like her." (Weisberger, p.213)

The excerpt above is a metaphor because it describes the staff in Runaway with robots. The researcher tries to compare between a person and a robot as mentioned in the excerpt 
above. The tenor of this metaphor is Runaway staffs and the vehicle is the usual robots. In denotative way, robots means a machine made by human in order to help human's physical activity and connotatively, robots means the employee who work like a robot, work for a busy job desk and long hours without any break because only robot who could do that however a human need to rest their body to prevent an exhaustion. The ground of this metaphor is both robot and the job have the similarity that would never feel exhausted.

\section{Tenor of Condition}

The researcher found there are some tenor metaphor of condition. The tenor metaphor of condition found refers to Andrea's condition within the novel. Andrea's conditions were interpreted by the vehicle in metaphor by Geoffrey Leech approach.

\section{Excerpt 5}

"Yeah, pretty much. But don't think that it'll be a joke. That will probably be the hardest week of all because she needs a lot of assistance when she's away. She'll be calling you a lot."

“Oh, goody,"I said. She rolled her eyes.

I slept with my eyes open, staring at a blank computer screen, until the office began to fill up, and there were other people to watch. Ten A.M brought the first of the Clackers, the quiet sipping no-whip skim lattes to nurse the previous night's champagne hangovers. James stopped by my desk, as he did whenever he saw Miranda wasn't at hers, and proclaimed he'd met his future husband at Balthazar the night before." (Weisberger, p.186)

The excerpt is a metaphor because it describes an overtime situation with slept with my eyes open. The researcher compares the situation of Andrea's bustle. The tenor of this metaphor is exhaustion and the vehicle is slept with my eyes open. The words I slept with my eyes open refers to Andrea's situation in the office when Miranda was in Paris. The metaphor refers to Andrea's overtime job, she could not sleep or even rest for a while. The only rest she had was sat in her office staring the computer screen all day meanwhile in denotative, slept with my eyes open is a condition of a person who sleep with their eyes open which is the person is fully rest and sleep but with their eyes open. The ground of this metaphor is an exhaustion situation of working all day.

"OK, listen. We have twenty to thirty seconds. You take Biarritz and the driver, I'll get Paris and the assistant," she called, her fingers already flying across the keypad. I double clicked on the thousand-plus name contact list that we shared on our hard drives and found exactly five numbers I'd have to call: Biarritz main, Biarritz second main, Biarritz studio, Biarritz pool, and Biarritz driver. A quick glance over the other listings for Karl Lagerfeld indicated that Emily had a grand total of seven, and there were still more numbers for New York and Milan. We were dead before we started. (Weisberger, p.230) 
The excerpt is a metaphor because it describes the panic situation with we were dead before we started. The researcher compares the situation over the metaphor. The tenor of this metaphor is panic situation and we were dead before we started as the vehicle. In connotative, the "dead" does not mean a person who literally dead, who left the world and out of breath instead the "dead" means their career would have been finished before they even finish their task. The ground of this metaphor is their career would have been finished before they complete the task.

\section{Tenor of Personality}

The researcher found there are some tenor metaphor of personality within the novel. The vehicle is used to interpret the personality of Andrea and Shauna. The researcher analyzes the tenor of metaphor using the figurative approach by Geoffrey Leech.

"Well, it seems she won't shut up! All it took was a little singing. I had a folk singer come in today to play the guitar for the kids, and Shauna was singing away. And once she broke the ice, she's been jabbering away with everyone since. She knows English. She has an age-appropriate vocabulary. She's completely and totally normal!" (Weisberger, p.272)

The excerpt is a metaphor because it describes a person with broke the ice. The tenor of this metaphor is Shauna and the vehicle is broke the ice. She was a silent girl who never speak to someone and finally started to sing, jabbered with everyone since and knew English. In connotative, "broke the ice" does not mean she broke an ice at the moment instead ice is a symbol of her silent situation that made the atmosphere cold without any words. When she finally speaks, it feels like she broke the cold situation by singing away. The ground of this metaphor is the moment Shauna spoke as same as she broke the silence which illustrated by the ice.

So when either of us needed help, the rest of the staff were obliged to pull through. Yes, of course there was something disconcerting about the realization that if we didn't work for Miranda Priestly these same people would have no compunction in running over us with their chauffeured Town Cars. As it was, when called upon, they ran and fetched and retrieved for us like well-trained puppies. (Weisberger, p.315)

The excerpt is a simile because it describes the other staff's personality with 'like' as the pointing word of simile. The tenor of this excerpt is the personality of other staff and welltrained puppies is the vehicle. The researcher explains that the simile like well-trained puppies refers to the other staff's behavior when Emily and Andrea needed help because a well-trained puppy do whatever their master tells them to do. Like well-trained puppies is not referring to a real puppy who is trained in the office.

\section{Tenor of Object}

The researcher found there are some tenor metaphor of object within the novel. The objects as the tenor is interpreted by the vehicle in metaphor by Geoffrey Leech. 
Things progressed with the same relative case until she asked her final question: Which magazines did I read regularly? I leaned forward eagerly and began to speak: 'Well, I only subscribe to The New Yorker and Newsweek, but I regularly read The Buzz. Sometimes Time, but it's dry, and U.S. News is way too conservative. (Weisberger, p.23)

The excerpt is a metaphor because Andrea tried to describe Time magazine with dry. The researcher compares the Time magazine with dry. The tenor of this metaphor is Time magazine and dry as the vehicle. In denotative way, dry means something that not wet or something that does not produce water but in this context, connotatively dry means something boring and nothing special. The ground of this metaphor is Time magazine is boring and flat magazine same as dry that has no any other elements included.

When I walked into my office area, Emily was sitting Indian-style on the floor, wrapping presents in plain white paper with white ribbons. She was surrounded by mountains of red - and - white boxes, all identical in shape, hundreds, perhaps thousands, scattered between our desks and overflowing into Miranda's office. (Weisberger, p.51)

The excerpt is a metaphor because it describes the boxes with mountains. The researcher compares the boxes with mountains. The tenor of this metaphor is the boxes and the vehicle is the mountain. In denotative way, mountains refer to some of the mountains which a land that protruding upwards higher than the other lands meanwhile in connotative way, the word mountains describes the pile of red and white boxes. The ground of this metaphor is the boxes were stacked like a mountain.

\section{Tenor of Sign}

The researcher found there is a tenor metaphor of sign within the novel that being interpreted by the vehicle. The sign in this case is a sign of Andrea to the delivery staff in order to send the package. This tenor of metaphor of sign was found by the figurative language approach by Geoffrey Leech.

Cut, place, fold, tape: Emily and I worked steadily through the morning, stopping only to call the downstairs messenger center each time we'd finished with twenty-five boxes. They'd hold them until we gave the green light for them to be fanned out all over Manhattan in midDecember. (Weisberger, p.64)

The excerpt is a metaphor because it describes a command with green light. The tenor of this metaphor is a command and green light as the vehicle. Connotatively, green light refers to a command of approving something, in this context, the green light means an approval of sending the gifts to all over Manhattan. The ground of this metaphor is something would make a move according to orders.

\section{Tenor of Emotion}

The researcher found there are some tenor metaphor of emotion portrayed by some character within the novel. The emotions were interpreted by the vehicle through the 
metaphor. The researcher uses figurative language approach by Geoffrey Leech to analyze the tenor metaphor of emotion.

Manoeuvring the green beast to head uptown sapped my last reserves of concentration, and by the time I reached Second Avenue, the stress sent my body into meltdown. It couldn't possibly get worse than this, I thought as yet another cab came within a quarter-inch of the back bumper. A nick anywhere on the car would guarantee I lose my job - that much was obvious - but it just might cost me my life as well. (Weisberger, p.5)

The tenor in the sentence is stress, it is an expression that come from any event that makes a person feels angry, frustrated or nervous. And the vehicle in the sentence is meltdown. Denotatively, meltdown is a process of frozen substances into water meanwhile in connotative, meltdown in this context means Andrea's body was so weak and she could not stand because of the stress. Therefore, it could be concluded that Andrea was stress and her body was limp, when someone feel limp, someone could not stand up straight or loses the energy same as meltdown.

We weren't in any rush to get back, though, somehow sensing that this would be the last period of calm before the craziness, and we stupidly extended our visas in Delhi so we could have a few extra weeks touring in the exotic countryside of India. Well, nothing ends the romance more swiftly than amoebic dysentery. (Weisberger, p.11)

The excerpt above is a metaphor, the researcher compares the word romance with amoebic dysentery. Tenor of this excerpt is love and amoebic dysentery as a vehicle. The ground of this metaphor is romance ends faster than amoeba dysentery.

\section{Metaphor and Simile Expressing the Emotion}

In this section, the researcher shows the excerpts found from quotations within the novel. The excerpts taken is considered as metaphor and simile by Geoffrey Leech which has a tenor, vehicle and ground to express the expression of emotion such as happy, angry, love, fear and sad, with the theory proposed by Kövecses, and would explain how the metaphor and simile are used to express the expression of emotion.

\section{Happy}

The researcher explains the figurative language such as metaphor and simile express the expression of happy found in the novel. There are three metaphor and one simile identified from the novel that used the vehicle to express the happy emotion in this research that would be discussed below.

"Andrea good morning hope I didn't call to early," Sharon sang her own voice full of sunshine. "I'm sure I didn't, my dear, especially since you'll have to be an early bird soon enough! I have some very good news" (Weisberger, p.26) 
In the excerpt above, the expression of happiness is compared to the sunshine. The researcher explains that a sunshine is used as the vehicle of the tenor a person who feels happy. The ground between the vehicle and the tenor is the happiness when someone would like to deliver good news. When people are happy, they always make a smile, laugh and some enthusiasm that could affect other people's mood and euphoria.

The sunshine produces an UV light that push a melanocyte, a cells that produce dark pigment in skin and release endorphins that could make a sense of comfort. The word sunshine is a vehicle of happiness in this sentence refers to Sharon voice through the phone that gave such a positive vibe and energetic voice as same as someone who get the sunshine. Whereas in the excerpt two below, a metaphor is used to describe a happiness of Andrea which is implied by the vehicle.

\section{Angry}

The researcher found there are metaphor and simile express the expression of angry found in the novel. There are three metaphor and two similes are identified from the novel that used the vehicle to express the angry emotion in this research that would be discussed below.

Emily's next written instruction was to pick up a pair of white shorts that Miranda desperately needed for Pilates. I figured we'd be headed to Polo, but she had written Chanel. Chanel made work-out wear? The driver took me to the private salon, where an older saleswoman whose facelift had left her eyes looking like slits handed me a pair of white cotton Lycra hot pants, size zero, pinned to a silk hanger and draped in a velvet garment bag. I looked at the shorts, which appeared as though they wouldn't fit a six-year old, and looked back to the woman.

"Um, do you really think Miranda will wear these?" I asked tentatively, convinced the woman could open that pit-bull mouth of hers and consume me whole. She glared at me. (Weisberger, p.50)

The excerpt above describes an anger emotion through the metaphor. The vehicle is used to express the anger emotion which is pit-bull mouth of hers and consume me whole. The vehicle did not mean Miranda has a mouth of pit-bull for real. The researcher explains the pit-bull mouth is a metaphor of Miranda's anger. Whenever Miranda gets angry, she would been barking as same as a dog, scolding everyone completely. The relation of the tenor which is an anger and the vehicle which is pit-bull mouth is a pit-bull, one of the breeds of dog, usually used for hunt and attack even large animals and the pit bull is an aggressive dog. This relation relates to the Miranda's character because she is an antagonist character especially to someone she does not like.

\section{Love}

Unlike the other emotion, the researcher only found the metaphor as the most of figurative language that express the expression of love in the novel. There are three metaphor 
identified from the novel that used the vehicle to express the love emotion in this research that would be discussed below.

Jack Tomlinson was B-DAD's younger and wilder brother, and he'd just announced he was leaving his wife and three children and marrying his masseuse. Although he and B-DAD were both quintessential East Coast prep school aristocracy, Jack had shed his Harvard persona in his late twenties and moved to South Carolina, where he'd immediately made a fortune in real estate. Judging from everything Emily had told me, he'd morphed into a first-class Southern boy, a real straw - chewin', tobaccospittin' hick, which of course appalled Miranda, the epitome of class and sophistication. B-DAD had asked Miranda to organize an engagement party for his baby brother, and Miranda, blinded by love, had no choice but to oblige. He had left all the details to her so, quite naturally, Miranda has set about to make things as difficult as humanly possible. (Weisberger, p.180)

The excerpt above contains a love emotion that expressed through the vehicle of metaphor. The vehicle blinded by love expresses the love emotion. The word blind does not mean completely blind, a people who unable to see caused by an injury, disease or congenital condition but blind in the excerpt above refers to Miranda's feeling to her husband. The researcher compares the love and blind. Miranda extremely hated her husband's brother but her husband asked Miranda to organize his birthday party therefore the author used blinded by love to interpret Miranda's feeling. She would do anything for her husband without any doubt even for someone she hates.

\section{Fear}

The researcher explains the figurative language such as metaphor and simile express the fear expression found in the novel. Unlike the other emotion, simile is the most common figurative language found that express fear emotion. There are one metaphor and three similes are identified from the novel that used the vehicle to express the fear emotion in this research that would be discussed below.

What part of that simple five-word sentence did she not comprehend, I wondered. Can't. Seem. To. Find. Him. Seemed rather clear and precise to me: We can't fucking find him. That is why you're not talking to him. If you can find him, then you can talk to him. A million barbed responses raced around my head, but I could only sputter like a first-grader who'd been singled out by the teacher for talking in class. (Weisberger, p.231)

The fear emotion is represented by a simile a first-grader who'd been singled out by the teacher for talking in class. The researcher explains the simile a first-grader who'd been singled out by the teacher for talking in class illustrates Andrea's fright because the relation between simile and Andrea's fright is she could do nothing than sputter as same as a student who is scolded for talking in class. The same emotion when a student is scolded by the teacher in class and could do nothing than sputter and tries to look for a reason. 


\section{CONCLUSION}

The researcher concludes that the tenor of occupation dominates the major of the sentence in this novel because this novel contains the struggle of Andrea in Runaway and followed with the tenor of emotion which is the aim of this research. The emotion of love is a form of emotion found mostly through the metaphor because in order to convince a partner. There are many metaphors of love that is used to get the partner's interest and would be an extra point in order to seduce a partner. The researcher also found that in simile, the most emotion portrayed is fear emotion because it is easier to use 'as' and 'like' to express the fear emotion, the use of simile only compares two things directly with 'as' or 'like' as the mediator unlike metaphor. The use of metaphor in order to deliver the emotion needs a word arrangement to compare things and make it an understandable metaphor.

\section{References}

Collins. (2020). Collins Dictionary. Retrieved from Collins 2020: https://www.collinsdictionary.com/dictionary/english/expression

Ekman, P. (1992). An Argument for Basic Emotions. San Francisco: Lawrence Erlbaum Associates Limited.

Kovecses, Z. (1990). Emotion Concepts. Budapest: Springer-Verlag New York Inc.

Leech, G. (1981). Semantics: The Study of Meaning Second Edition. Auckland: Penguin Books.

(1969). A Linguistic Guide to English Poetry. New York: Longman Inc.

Miller, G. R. (1981). Poetry an introduction. New York: St. Martin's Press, Inc.

Peter. (2002). Figurative language and semantics. Boston: Little Brown and Company. 